\title{
Avaliação sensorial de produtos panificados com adição de farinha de bagaço de maçã
}

\author{
Sensory evaluation of bakery products with the addition of apple pomace flour
}

\author{
Laylla Marques COELHO ${ }^{1 *}$, Gilvan WOSIACKI²
}

\section{Resumo}

A industrialização da maçã, em particular do suco, gera, no processamento, como principal resíduo ou subproduto, o bagaço, e como gerenciá-lo adequadamente está entre as prioridades das indústrias processadoras. A composição físico-química da farinha de bagaço de maçã apresentou, neste estudo, $43 \%$ de fibras em base seca. Os estudos sobre as fibras demonstram que elas exercem uma ação hipocolesterolêmica, reduzindo a digestão e a absorção dos lipídios dietéticos, aumentando a excreção fecal dos ácidos biliares e esteróis neutros, aumentando a produção de ácidos graxos de cadeia curta no cólon e diminuindo a porcentagem de ácidos biliares primários na bile. O objetivo deste estudo foi avaliar sensorialmente produtos panificados, adicionados de farinha de bagaço de maçã, e comprovar que a farinha de bagaço de maçã pode constituir fonte alternativa potencial de fibra alimentar para a formulação de alimentos panificados.

Palavras-chave: aproveitamento de resíduos agroindustriais; farinha de bagaço de maçã; fibras alimentares; produtos de panificação.

\begin{abstract}
The industrialization process of apple, particularly juice, generates the pomace as the main residue or by-product, whose proper management should be among the priorities of the processing industries. The physicochemical composition of the apple pomace flour obtained in this study consisted of $43 \%$ of fiber on a dry basis. Studies on the fibers show that they have a hypocholesterolemic action reducing the digestion and absorption of dietary lipids, increasing the fecal excretion of bile acids and neutral sterols, increasing the production of short-chain fatty acids in the colon, and decreasing the percentage of primary bile acids. The objective of this study was to evaluate sensorially bakery products added with apple pomace flour to show that the apple pomace flour can be a potential alternative source of dietary fibers in bakery products.
\end{abstract}

Keywords: agro-industriail residues recovery; apple pomace flour; fiber; bakery products.

\section{Introdução}

A gestão agroindustrial preconiza uma tecnologia limpa com o gerenciamento adequado dos resíduos produzidos em meio agrícola e nas indústrias derivadas. A produção de bagaço de maçãs no Brasil foi estimada em 50.000 toneladas de bagaço fresco, em 2007, a partir dos dados de produção e industrialização.

O resíduo de extração (bagaço) apresenta-se como o principal subproduto gerado na agroindústria da maçã (HANG, 1987). O resultado dessa extração compreende as cascas e polpa $(94,5 \%)$, as sementes $(4,4 \%)$ e os centros $(1,1 \%)$. O conteúdo de açúcares totais é elevado, cerca de $40 \%$ em base seca, mas pode apresentar menores teores com alterações no processamento de extração de suco.

Quanto ao bagaço de maçã, se os resíduos forem adequadamente desidratados, podem ser secos até que contenham menos de $10 \%$ de umidade a fim de ser armazenado e servir como matéria-prima para a obtenção de componentes de alto valor agregado com pectinas (LEVIN, 1989; WOSIACKI, 2005). Na literatura científica, é possível encontrar alguns processos que visam a utilização do bagaço seco, sob a forma de farinha, na elaboração de produtos de panificação e massas alimentícias, com o intuito de obter alimentos rico em fibras alimentares, principalmente pectina, e açúcares solúveis (CARSON; COLLINS; PENFIELD, 1994; CHEN et al., 1988a; RENARD; TRIBALT, 1991; WANG; THOMAS, 1989; PROTZEK et al., 1998a).

A indústria brasileira de processamento da maçã tem demonstrado interesse em alternativas econômicas e tecnologicamente viáveis para a utilização do descarte sólido produzido. Apesar disso, estes produtos continuam a ser considerados, embora quantitativamente relevantes, apenas como resíduos, produtos sem valor econômico. A perda de dinheiro, de nutrientes potenciais e de qualidade do ar nas regiões de processamento é marcante, uma vez que o resíduo fermenta e exala odores. Há necessidade, pois, de que se procure caracterizar as matérias sólidas produzidas durante o processamento de suco e de sidra, e se busquem alternativas de uso com finalidades mais nobres do que aquelas que vêm sendo praticadas nas regiões de industrialização (RAUPP; MOREIRA; BANZATTO, 1999).

Recebido para publicação em 25/7/2008

Aceito para publicação em 7/7/2009 (002829)

${ }^{1}$ Departamento de nutrição, Associação Educacional Luterana Bom Jesus - IELUSC, CEP 8705020, Joinville - SC, Brasil, E-mail: layllamc@yahoo.com.br

${ }^{2}$ Departamento de Engenharia de Alimentos, Universidade Estadual de Ponta Grossa - UEPG, CEP 84030-900, Ponta Grossa - PR, Brasil

${ }^{*}$ A quem a correspondência deve ser enviada 
Algumas propostas visando aproveitar, para fins alimentícios, a matéria sólida produzida nas unidades industriais de maçã foram desenvolvidas por pesquisadores da comunidade científica mundial, incluindo a do Brasil e, na maioria, foi determinada a caracterização química e física. Também se avaliou o aproveitamento dessa matéria sólida como ingrediente de alimentos formulados, como para os produtos da panificação e outros. Em contraste, pouco tem sido feito com relação à avaliação de suas propriedades in vivo, funcionais-digestivas e nutricionais (WALTER et al., 1985; HANG, 1987; CHEN et al., 1988; CHEN; RUBENTHALER; SCHANUS, 1988; WANG; THOMAS, 1989; RENARD; TRIBAULT, 1991; SAURA CALIXTO, 1993; CARSON; COLLINS; PENFIELD , 1994; PROTZEK et al., 1998a; RAUPP; SGARBIERI, 1997).

Alimentos funcionais ou nutracêuticos são termos utilizados para caracterizar alimentos e/ou ingredientes alimentares que, além de suas funções nutricionais normais (fonte de energia e substrato para a formação de células e tecidos), possuem, em sua composição, uma ou mais substâncias capazes de atuar como moduladores dos processos metabólicos, melhorando as condições de saúde, promovendo o bem-estar e prevenindo o surgimento precoce de doenças degenerativas. Os alimentos funcionais representam uma união da farmacologia com a tecnologia de alimentos na busca de uma melhor qualidade de vida, baseada na alimentação. Isso vem sendo reconhecido pelo consumidor moderno, que tem procurado com mais frequência esse tipo de produto nas prateleiras dos mercados. Evidentemente, esses alimentos não podem ser encarados como uma solução única, mas sim como mais um auxílio que os avanços tecnológicos e científicos colocam à disposição (SKLIUTAS, 2002).

As indústrias de alimento têm grandes expectativas de que seus produtos atendam à demanda dos consumidores por um estilo de vida mais saudável. Neste contexto, o alimento funcional desempenha um papel específico. Estes alimentos não visam somente satisfazer a fome ou prover os nutrientes necessários, mas também prevenir doenças e aumentar o bem-estar físico e mental destes consumidores (MENRAD, 2003).

O aumento da fibra solúvel na dieta alimentar pode desempenhar um papel importante no tratamento da obesidade por aumentar a sensação de plenitude e saciedade e, assim, reduzir a ingestão diária de calorias (JUDD; TRUSWELL, 1982; KROTKIEWSKI, 1984).

A relação entre o consumo de fibra alimentar e a incidência das enfermidades gastrointestinais tem sido demonstrada (TUNGLAND; MEYER, 2002). Na África, onde o consumo médio é de até $150 \mathrm{~g}$ fibras ao dia, a população não apresenta enfermidades como a constipação crônica, diverticulose e cólon irritável. Por outro lado, em países industrializados, onde a população possui um consumo de fibras consideravelmente menor (aproximadamente $15 \mathrm{~g} / \mathrm{dia}$ ), ocorre um número muito alto destas enfermidades, desencadeando o preocupante aumento da incidência e mortalidade pelo câncer colorretal (MARQUÊZ, 2001).

O trabalho buscou obter farinha de bagaço de maçã para fins alimentares, determinando suas características físico-químicas, e desenvolver um produto alimentar para um ensaio de avaliação de custo/benefício e sensorial: os produtos panificados adicionados da farinha de bagaço de maçã.

\section{Material e métodos}

\subsection{Processamento da maçã}

$\mathrm{Na}$ produção da farinha de bagaço de maçã, foram utilizados 450 kg de maçã Fuji, safra 2006, de tamanho médio, fisiologicamente maduras e de coloração vermelha, adquiridas no comércio local de Ponta Grossa - PR.

As maçãs foram selecionadas, desinfetadas e lavadas em água clorada a $1 \%$, cortadas com faca e trituradas em moinho de facas, marca Metvisa. A massa ralada foi acondicionada em telas de polietileno superpostas entre placas de madeira revestidas e prensada a $3 \mathrm{kgf.cm}{ }^{-2}$ em equipamento hidráulico (Hydraulica Press Eureka, Senger), por 15 minutos, extraindo-se o suco e obtendo-se um bagaço fresco e úmido.

\subsection{Beneficiamento da farinha de bagaço de maçã}

O bagaço fresco e úmido foi lavado com água tratada fluoretada em temperatura ambiente, numa proporção 2:1, por duas vezes, para retirada dos sólidos solúveis superficiais, tendo-se um líquido de lavagem com, no máximo, $2^{\circ} \mathrm{Brix}$, centrifugado em equipamento eletrodoméstico por 5 minutos (PAGANINI et al., 2005) e colocado em estufa a $60^{\circ} \mathrm{C}$, com circulação de ar, por 24 horas.

O bagaço frio foi moído em moinho de martelos com peneira de tamis de 60 mesh, obtendo-se a farinha de bagaço de maçã, que foi armazenada em recipientes hermeticamente fechados.

O método de obtenção está ilustrado na Figura 1.

\subsection{Obtenção dos produtos alimentícios contendo farinha de bagaço de maçã}

Foi utilizada balança Filizola com capacidade máxima de $15 \mathrm{Kg}$ para pesagem dos ingredientes; liquidificador e batedeira eletrodoméstica da marca Walita para mistura dos produtos; e, para assar os panificados, forno industrial.

Com a realização de testes preliminares, determinou-se a formulação mais adequada para a produção dos produtos adicionados de farinha de bagaço de maçã. Os produtos foram biscoitos, pão, pão de queijo, bolo e vitaminas, conforme Tabela 1.

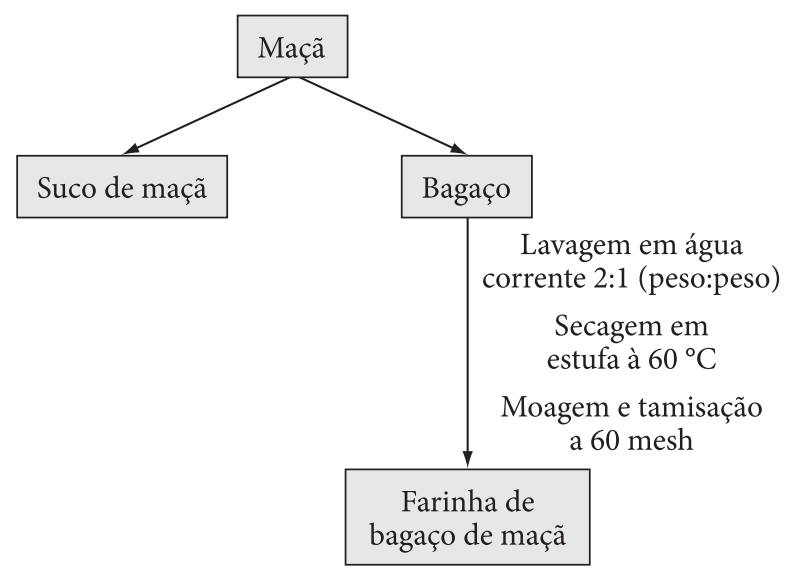

Figura 1. Fluxograma da produção de farinha de bagaço de maçã. 


\subsection{Análises químicas, físicas e microbiológicas}

A farinha de bagaço de maçã foi analisada com relação aos parâmetros de qualidade, realizados em triplicata.

A umidade foi determinada por perda termogravimétrica a $110^{\circ} \mathrm{C}$ (INSTITUTO..., 1985 ) e cinzas, a $550^{\circ} \mathrm{C}$ (ASSOCIATION... 1980). Os teores de proteína foram calculados multiplicando-se por 6,25 a quantidade de nitrogênio determinada após destilação por arraste da amostra digerida com mistura catalítica. O extrato etéreo foi calculado por perda gravimétrica da amostra após remoção com éter de petróleo (OSBORNE; VOOGT, 1986). Os açúcares redutores totais, após hidrólise da sacarose com $\mathrm{HCl} 1 \mathrm{~N}$ por 5 minutos a $65^{\circ} \mathrm{C}$, foram determinados pela metodologia clássica de Somogyi modificada por Nelson, tendo sido expressos como glucose em g. $100 \mathrm{~g}^{-1}$. As fibras alimentares foram determinadas por gravimetria após hidrólise proteica e amilolítica com enzimas comerciais (Pepsina, Termamyl e AMG).

Os teores de glucose foram determinados pela metodologia da oxidação a ácido glicônico mediante o kit GOD. Os teores de frutose foram calculados por exclusão dos valores de glucose da fração açúcares solúveis.

A análise granulométrica foi feita utilizando tamises de 9 a 60 mesh, submetidas à ação de vibrador pelo período de 10 minutos (FARMACOPEIA..., 1988) e atividade de água-Aw, em aparelho Braseq (POMBO, 1987).

Tabela 1. Formulação para a elaboração dos produtos adicionados de farinha de bagaço de maçã.

\begin{tabular}{|c|c|c|}
\hline \multicolumn{3}{|c|}{ Biscoito com farinha de bagaço de maçã } \\
\hline Ingrediente & Quantidade (g) & $\%$ \\
\hline Ovos & 150 & 10 \\
\hline Açúcar refinado & 300 & 20 \\
\hline Sal amoníaco & 30 & 2 \\
\hline Creme de leite & 80 & 5 \\
\hline Farinha de trigo & 480 & 30 \\
\hline Farinha de bagaço de maçã & 300 & 20 \\
\hline Água morna & 100 & 6,5 \\
\hline Leite morno & 100 & 6,5 \\
\hline \multicolumn{3}{|c|}{ Vitamina com farinha de bagaço de maçã } \\
\hline Banana & 80 & 4 \\
\hline Leite desnatado & 1000 & 45 \\
\hline Água & 1000 & 45 \\
\hline Farinha de bagaço de maçã & 100 & 6 \\
\hline \multicolumn{3}{|c|}{ Pão com farinha de bagaço de maçã } \\
\hline Massa de pão caseiro & 2000 & 83 \\
\hline Farinha de bagaço de maçã & 400 & 17 \\
\hline \multicolumn{3}{|c|}{ Pão de queijo com farinha de bagaço de maçã } \\
\hline Mistura para pão de queijo pronta & 200 & 24 \\
\hline Ovos & 150 & 18 \\
\hline Leite desnatado & 200 & 24 \\
\hline Farinha de bagaço de maçã & 300 & 34 \\
\hline \multicolumn{3}{|c|}{ Bolo com farinha de bagaço de maçã } \\
\hline Mistura para bolo pronto & 100 & 8 \\
\hline Ovos & 150 & 12 \\
\hline Leite desnatado & 700 & 55 \\
\hline Farinha de bagaço de maçã & 300 & 24 \\
\hline
\end{tabular}

O rendimento da produção foi determinado pela relação entre a massa do fruto in natura e após beneficiamento da farinha, determinada em balança semianalítica, em três repetições.

Os dados das análises físicas e químicas, em triplicata, da farinha de bagaço de maçã foram submetidos à análise de variância (ANOVA) e teste de média Tukey, a 5\% de significância.

As análises microbiológicas foram de contagem de coliformes fecais (NMP.g ${ }^{-1}$ ), bolores e leveduras (UFC. $\mathrm{g}^{-1}$ ), contagem de Staphylococcus aureus (UFC. $\mathrm{g}^{-1}$ ), Bacillus cereus (UFC.g ${ }^{-1}$ ) e Salmonella (sp.25 g ${ }^{-1}$ ).

\subsection{Análise sensorial}

Foram feitas duas análises sensoriais, uma com vitamina de banana adicionada de farinha de bagaço de maçã, com 43 julgadores não treinados e outra com bolo adicionado de farinha do bagaço de maçã, com 35 julgadores não treinados, selecionados aleatoriamente no laboratório de análise sensorial da Universidade Estadual do Centro-Oeste do Paraná UNICENTRO, numa faixa de 20 a 70 anos, de ambos os sexos.

Os produtos preparados foram avaliados utilizando-se a escala hedônica estruturada de 9 pontos, onde 9 representa a nota máxima "gostei muitíssimo" e 1, a nota mínima "desgostei muitíssimo" (ASSOCIAÇÃO..., 1998). Foi solicitado a cada julgador que explicitassem também os aspectos que gostaram e não gostaram nas amostras.

Os dados gerados pelos resultados da análise sensorial foram submetidos à análise estatística utilizando-se a análise de diferença das médias de acordo com o Teste de Tukey's Honestly Significant Difference (HSD).

\section{Resultados e discussão}

\subsection{Beneficiamento da farinha do bagaço de maçã}

Dos $450 \mathrm{Kg}$ de maçã Fuji in natura, foram processadas $412 \mathrm{Kg}$, obtendo-se $170 \mathrm{Kg}$ de bagaço fresco não lavado, $148 \mathrm{Kg}$ de bagaço fresco lavado e $22 \mathrm{Kg}$ de farinha de bagaço de maçã, seca e moída. O rendimento, após o processo de desidratação, foi de 5,33\% em relação à matéria-prima.

Os rendimentos observados em outros estudos com farinha de bagaço de maçã demonstraram valores de 5 a $7 \%$, dependendo do tipo de secagem realizada e da temperatura a que foi submetida (PROTZEK et al., 1998b; NOGUEIRA et al., 2005; RAUPP; MOREIRA; BANZATTO, 1999)

\subsection{Caracterização da qualidade da farinha do bagaço de maçã}

Os resultados obtidos para valores das análises granulométricas da farinha de bagaço de maçã são apresentados na Tabela 2. 
Os dados demonstram que $59,26 \%$ da farinha apresentaram uma granulometria pequena, menor que 60 mesh, o que é esperado e satisfatório para as características de farinha.

A Atividade de água $(\mathrm{Aw})$ da farinha de bagaço de maçã foi de 0,81 , demonstrando ser um produto estável do ponto de vista microbiológico, uma vez que não possibilita o crescimento de leveduras, fungos e bactérias termófilas. Apresenta durabilidade semelhante a das farinhas comerciais, uma vez que tem atividade de água equivalente, desde que seja armazenada em embalagem adequada, à temperatura ambiente.

Os resultados obtidos quanto às análises químicas estão apresentados na Tabela 3.

O bagaço da maçã apresenta composição química dependente do processo de obtenção (tipo de moagem e processo de extração dos sólidos solúveis) e de beneficiamento (tempo e temperatura de desidratação). Em termos de umidade, o valor encontrado de 7,10 g.100 g-1 confere boa estabilidade físico-química ao produto, com um tempo de conservação longo, desde que armazenado adequadamente. Os resultados apresentados por Sato et al. (2007), com 11 variedades distintas, demonstraram valores médios de 11,43 g.100 g-1, que variaram

Tabela 2. Distribuição do tamanho de partículas da farinha de maçã.

\begin{tabular}{lcc}
\hline Peneiras $\left(\mathrm{US} \mathrm{n}^{\circ}\right)$ & Abertura $(\mathrm{mm})$ & Farinha de maçã $(\%)^{1}$ \\
\hline Granulometria $2 \mathrm{~mm}$ & 9 & 1,79 \\
Granulometria $1,7 \mathrm{~mm}$ & 10 & 0,87 \\
Granulometria $1 \mathrm{~mm}$ & 18 & 3,40 \\
Granulometria $0,85 \mathrm{~mm}$ & 20 & 3,97 \\
Granulometria 0,50 mm & 35 & 30,71 \\
Fundo <0,5 mm & 60 & 59,26 \\
\hline
\end{tabular}

1- Médias aritméticas de três repetições do material retido sobre as peneiras \pm desvio padrão.

Tabela 3. Composição físico-química da farinha de bagaço de maçã.

\begin{tabular}{lc}
\hline Componentes & $\mathrm{g} .100 \mathrm{~g}^{-1}$ \\
\hline Umidade & 7,10 \\
Gordura & 1,31 \\
Fibra alimentar & 43,02 \\
Fibra solúvel & 17,65 \\
Fibra insolúvel & 25,37 \\
Proteína bruta & 3,35 \\
Resíduo mineral & 1,46 \\
Açúcar redutor total & 35,11 \\
Glicose & 6,15 \\
Frutose & 22,31 \\
Sacarose & 6,65 \\
\hline
\end{tabular}

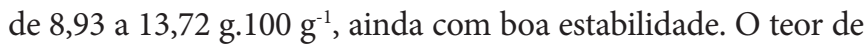
cinzas de 1,46 g.100 g $\mathrm{g}^{-1}$ está compatível aos citados por Hwang (1993), Marcon et al. (2005) e Sato et al. (2007) e se refere aos minerais retidos no bagaço, não lixiviados no processo de reidratação e prensagem. O teor de proteína de 3,35 g.100 g-1 está mais compatível com os resultados de Hwang (1993) e de Sato et al. (2007) do que com os de Marcon et al. (2005), embora o tipo de processamento e de procedimentos de análise tenha sido o mesmo; e o teor de lipídios, de 1,31 g.100 g-1 , está entre os valores relatados por estes autores.

O teor de açúcares totais $\left(35,11 \mathrm{~g} .100 \mathrm{~g}^{-1}\right)$, retidos nos restos de paredes celulares e não extraídos com água, na literatura, os valores encontrados são da mesma magnitude, como 39,13 g.100 g-1 (SATO et al., 2007), 38,3 g.100 g-1 (HWANG, 1993) e bem mais baixos como $22,5 \mathrm{~g} .100 \mathrm{~g}^{-1}$ (JOSHI; KAUSHAL, 1995). O teor de fibras é alto (43,02 g.100 g-1), como o de Sato et al. (2007) que foi de $43,71 \mathrm{~g} .100 \mathrm{~g}^{-1}$, embora outros autores tenham encontrado valores menores, como 20 g. $100 \mathrm{~g}^{-1}$ (JOSHI; KAUSHAL, 1995).

É possível observar que as características de qualidade físicoquímica de bagaço de maçã são muito dependentes das operações de beneficiamento e dos métodos de análise empregados, além das diferenças varietais. Os resultados apresentados por Marcon et al. (2005) referem-se à variedade Gala; os de Sato et al. (2007), a 11 variedades experimentais; e os de Joshi e Kaushal (1995) e Hwang (1993), a uma mistura de variedades industriais. A composição da farinha de bagaço de maçã é comparável à apresentada na literatura.

Os resultados microbiológicos e sua comparação aos padrões microbiológicos estão na Tabela 4 .

De acordo com a Tabela 4, a farinha de bagaço de maçã apresentou características microbiológicas adequadas, uma vez que os valores obtidos estão abaixo dos padrões exigidos na legislação brasileira.

\subsection{Análise sensorial de alimentos com farinha de bagaço de maçã}

Análise sensorial da vitamina de banana com farinha de bagaço de maçã

Na Figura 2, estão apresentadas as avaliações sensoriais, em escala hedônica com notas de 1 a 9, de desgostei extremamente a gostei extremamente.

Tabela 4. Análises microbiológicas da farinha do bagaço de maçã.

\begin{tabular}{|c|c|c|}
\hline Determinações & Farinha de bagaço de maçã & Padrões microbiológicos exigidos na legislação brasileira* \\
\hline Contagem de coliformes fecais NMP.g ${ }^{-1}$ & $<3$ & $10 . g^{-1}($ máx.) \\
\hline Contagem de bolores e leveduras UFC.g ${ }^{-1}$ & $<10^{2}$ & $10^{4} \cdot \mathrm{g}^{-1}($ máx. $)$ \\
\hline Contagem de Staphylococcus aureus UFC. $\mathrm{g}^{-1}$ & $<10^{2}$ & $5 \times 10^{2} \cdot \mathrm{g}^{-1}$ (máx.) \\
\hline Contagem de Bacillus cereus UFC.g ${ }^{-1}$ & $<10^{2}$ & $10^{3} \cdot \mathrm{g}^{-1}$ (máx.) \\
\hline Pesquisa de Salmonella sp. $25 \mathrm{~g}^{-1}$ & Ausência & Ausência em $25 \mathrm{~g}$ \\
\hline
\end{tabular}


O valor médio obtido para a amostra foi de 7,34 que, na escala hedônica utilizada na análise sensorial, corresponde ao gostei moderadamente.

As amostras de vitamina de banana com adição de farinha de bagaço de maçã, segundo o teste de escala hedônica, não apresentaram diferenças significativas quanto à aceitabilidade $(\mathrm{p}>0,05)$. A média entre as amostras revelou notas 7 e 8 (gostei moderadamente/gostei muito), mostrando uma ótima aceitação do produto.

Os aspectos sensoriais que os julgadores menos gostaram foram: consistência excessiva $(27,91 \%)$, a textura encontravase pastosa, o que pode não agradar o paladar individual; gosto amargo residual (25,58\%), devido à oxidação da maçã in natura sem aquecimento; textura (16,28\%), citado semelhante ao primeiro aspecto; cor $(9,3 \%)$, pois a cor do produto é escura, devido à oxidação, não ocorrendo quando havia adição de sucos que contêm ácido cítrico; e pouco doce (9,3\%), pois a adição de açúcar foi de $10 \%$, o que poderia ter sido maior.

Os compostos fenólicos estão relacionados aos princípios amargos da maçã e compreendem os ácidos clorogênicos e seus ésteres, entre muitos outros componentes, sendo os resultados de suas análises expressos como catequinas em ppm (WOSIACKI; PHOLMAN; NOGUEIRA, 2004). Além disso, os compostos fenólicos têm demonstrado sua importância face às influências em outras características sensoriais, como a cor, formação de certos aromas e capacidade antioxidante que contribui para a proteção dos efeitos prejudiciais ocasionados pelo stress oxidativo sobre a saúde (SHAHIDI; NACZK, 1995; NOGUEIRA, 2003).

\section{Análise sensorial do bolo com farinha de bagaço de maçã}

$\mathrm{Na}$ Figura 3, são apresentadas as avaliações sensoriais, em escala hedônica com notas de 1 a 9, de desgostei extremamente a gostei extremamente.

O valor médio obtido para a amostra foi de 7,31 que, na escala hedônica utilizada na análise sensorial, corresponde ao gostei moderadamente.

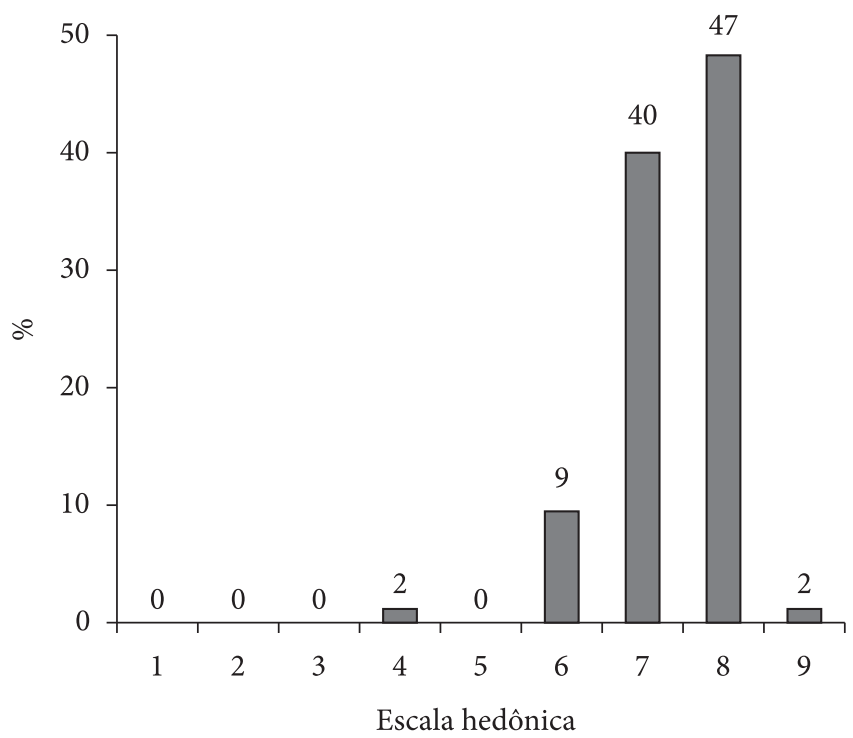

Figura 2. Resultados da análise sensorial da vitamina com farinha de bagaço de maçã.
A amostra de bolo adicionado de farinha de bagaço de maçã, segundo o teste de escala hedônica, apresentou média entre notas 7 e 8 (gostei moderadamente/gostei muito), mostrando a aceitação do produto.

Os aspectos sensoriais que os julgadores menos gostaram foram: pouco doce $(11,43 \%)$, reafirmando que a quantidade de açúcar necessário é uma escolha individual; pedaço ser pequeno $(8,57 \%)$, demonstrando que houve uma grande aceitação e se pudessem comeriam mais do que o oferecido; consistência (5,71\%), individualmente algumas pessoas preferem bolos com consistência mais firme, o que não ocorreu; gosto amargo residual $(5,71 \%)$, que estava bem menos acentuado que na vitamina, mas se apresentava no produto.

A massa do bolo é uma emulsão complexa de gordura em água, composta de bolhas como fase descontínua e de uma mistura de ovo-açúcar-água-gordura como fase contínua, na qual partículas de farinha estão dispersas (KOCER et al., 2007).

Os parâmetros de qualidade mais importantes de bolos são a textura, a cor, o teor de umidade, a densidade e o $\mathrm{pH}$, os quais podem ser mensurados. As cinéticas de todos estes parâmetros são controladas pela transferência de massa e de calor. Estes parâmetros variam não apenas devido à variação da temperatura de forneamento, mas também devido à estrutura do forno e à umidade e velocidade do ar no interior do forno (BAIK et al., 2000).

O estudo de Lee, Inglett e Carriere (2004) avaliou os efeitos da substituição parcial da margarina por farelo de aveia (Nutrim $\mathrm{OB})$ e linhaça sobre as propriedades físicas e reológicas de bolos. Os autores observaram que a coesividade diminuiu e a maciez aumentou gradualmente com o aumento da substituição, demonstrando que a quantidade de farinha de bagaço de maçã utilizado, que foi de $24 \%$, também reduziu coesividade e aumentou maciez.

Protzek et al. (1998a) estudaram o aproveitamento do bagaço da maçã para a produção de biscoitos ricos em fibras, e apresentaram boa aceitação entre os consumidores, além de

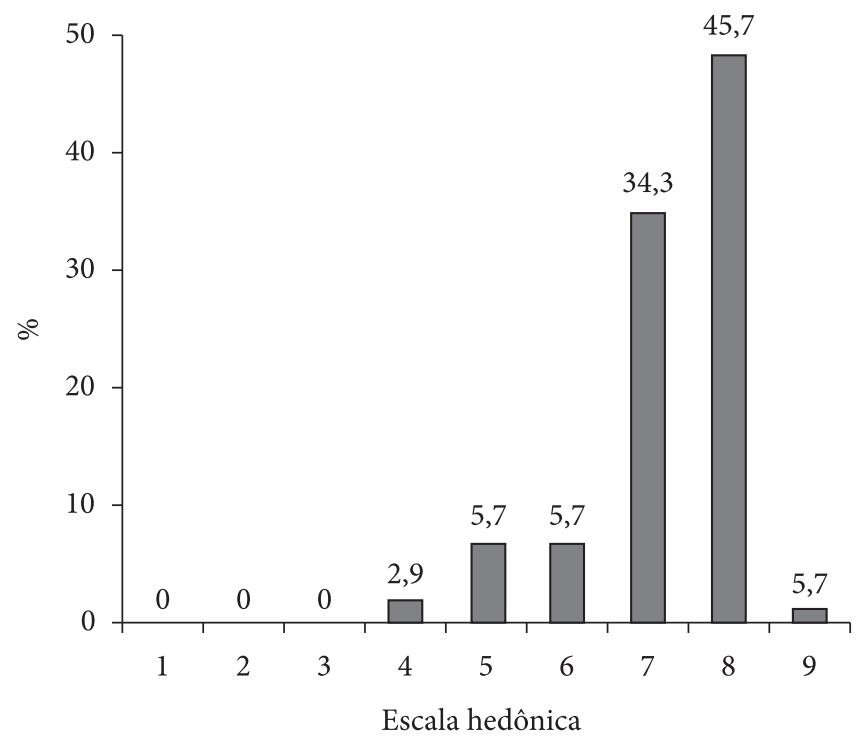

Figura 3. Resultados da análise sensorial do bolo com farinha de bagaço de maçã. 
apresentar elevado potencial como fonte de fibras alimentares. $\mathrm{Na}$ panificação, a farinha de bagaço de maçã também mostrou ser um ingrediente em potencial para enriquecimento de produtos com fibra alimentar, e concluiu-se que os pães com melhor aceitação foram aqueles elaborados com níveis de 5 e $10 \%$ de farinha de bagaço de maçã (PROTZEK et al., 1998b)

Por meio destas pesquisas, pode-se afirmar que, além dos produtos à base de maçã comercialmente conhecidos, outros produtos, como bolos, biscoitos, pães, e a incorporação a vitaminas e mingaus podem ser feitos utilizando como ingrediente o bagaço da maçã.

A partir do levantamento sensorial, foi possível constatar a aceitação dos produtos com farinha de bagaço de maçã, o que torna possível a utilização dos produtos na panificação.

\section{Conclusões}

O bagaço desidratado de maçã, nas condições do processamento empregado, apresentou um rendimento de $5,33 \%$ em relação à matéria-prima;

A composição físico-química da farinha de bagaço de maçã, fortemente influenciada pelo tipo de processamento, apresentou $43 \%$ de fibras em base seca, incluindo as pectinas. O teor de umidade de $7 \%$ propicia um armazenamento a longo prazo, desde que mantida em frascos hermeticamente fechados;

A farinha de bagaço de maçã pode constituir fonte alternativa potencial da fibra alimentar para a formulação de alimentos, que apresentem propriedades específicas relacionadas à fibra alimentar/dietética, destinados ao consumo humano; e

Os produtos vitamina de banana e bolo, contendo farinha de bagaço de maçã, foram bem aceitos pela equipe sensorial não treinada, com notas de 7-8 na escala hedônica, para ambos.

\section{Agradecimentos}

Agradeço este estudo a meu orientador Gilvan Wosiacki, um homem fomentador de ideias e um visionário.

\section{Referências bibliográficas}

ASSOCIAÇÃO BRASILEIRA DE NORMAS TÉCNICAS - ABNT. NBR 14141: escalas utilizadas em análise sensorial de alimentos e bebidas. Rio de Janeiro, 1998.

ASSOCIATION OF OFFICIAL AGRICULTURE CHEMISTS - AOAC. Official methods of analysis association of official agriculture chemists $30^{\text {th }}$ ed. [S.1.], 1980.

BAIK, O. D.; MARCOTTE, M.; CASTAIGNE, F. Cake baking in tunnel type multi-zone industrial ovens. Part II. Evaluation of quality parameters. Food Research International, v. 33, p. 599-607, 2000.

BRASIL. Ministério da Saúde. Agência Nacional de Vigilância Sanitária. Resolução - RDC no 12, de 2 de janeiro de 2001. Aprova "regulamento técnico sobre padrões microbiológicos para alimentos”. Diário Oficial [da] República Federativa do Brasil, Brasília, DF, 2 jan. 2001. Disponível em: <http://e-legis.bvs.br/ leisref/public/showAct.php?id=144>. Acesso em: 29 dez. 2006.

CARSON, K. J.; COLLINS, J. L.; PENFIELD, M. P. Unrefined, dried apple pomece as a potencial food ingredient. Journal of Food Science, v. 59, n. 6, p.1213-1215, 1994.
CHEN, H. et al. Chemical, physical and baking properties of apple fiber compared with wheat and oat bran. Cereal chemistry, v. 65, n. 3, p. 244-247, 1988.

CHEN, H.; RUBENTHALER, G. L.; SCHANUS, E. G. Effect of apple fiber and cellulose on the physical properties of wheat flour. Journal of Food Science, v. 53, p. 304-305, 1988 b.

FARMACOPEIA Brasileira. 4 ed. São Paulo: Atheneu, 1988.

HANG, Y. D. Production of fuels and chemicals from apple pomace. Food Technology, v. 41, n. 3, p. 115-117, 1987.

HWANG, J. Purification and analysis of pectins. Journal of Korean Society of Food Science and Nutrition, v. 22, n. 4, p. 500-509, 1993.

INSTITUTO ADOLFO LUTZ. Normas analíticas do Instituto Adolfo Lutz. Métodos químicos e físico para análises de alimentos. 3 ed. São Paulo, 1985.

JOSHI, V. K.; KAUSHAL, N. K. Composition of apple pomace, standardization of pulp making, preparation and evaluation of apple pomace jam. Research and Industry, v. 40, n. 3, p. 203-207, 1995

JUDD, P. A.; TRUSWELL, A. S. Comparasion of the effects of hight and low methoxyl pectin on blood and faecal lipids in man. British Journal of Nutrition, v. 48, n. 3, p. 451-458, 1982.

KOCER, D. et al. Bubble and pore formation of the high-ratio cake formulation with polydextrose as a sugar- and fat-replacer. Journal of Food Engineering, v. 78, p. 953-964, 2007.

KROTKIEWSKI, M. Effect of guar gum on body-weight hunger ratings and metabolism in obese subjects. British Journal of Nutrition, v. 52, n. 1, p. 97-105, 1984.

LEE, S.; INGLETT, G. E.; CARRIERE, C. J. Effect of Nutrim oat bran and flaxseed on rheological properties of cakes. Cereal Chemistry, v. 81, n. 5 , p. 637-642, 2004.

LEVIN, R. J. Dietary carbohydrate and kinetics ofintestinal functions in relation to hexose absorption. In: DOBBING, J. Dietary starches and sugars in man: a comparison. New York: Springer-Verlag, 1989. p. $87-117$.

MARCON, M. V. et al. Pectins from apple pomace. Polímeros: Ciência e Tecnologia, v. 15, n. 2, p. 127-129, 2005.

MARQUÊZ, L. R. Fibra Terapêutica. Nutrição em Pauta, 2001.

MENRAD, K. Market and marketing of functional food in Europe. Journal of Food Engineering, v. 56, p. 181-188, 2003.

NOGUEIRA, A. et al. Aproveitamento de bagaço de maçã para a produção de álcool e obtenção de fibras alimentares. Ciência e Agrotecnologia, v. 29, n. 6, p. 179-186, 2005.

NOGUEIRA, A. Tecnologia de processamento sidrícola. Efeitos do oxigênio e do nitrogênio na fermentação lenta da sidra. $210 \mathrm{f}$. Tese (Doutorado em Processos Biotecnológicos Agroindustriais) Universidade Federal do Paraná, Curitiba, 2003.

OSBORNE, D. R.; VOOGT, P. Analise de los nutrients de los alimentos. Zaragoza: Acribia, 1986.

PAGANINI, C. et al. Aproveitamento de bagaço de maçã para a produção de álcool e obtenção de fibras alimentares. Ciência e Agrotecnologia, v. 29, n. 6, p. 1231-1238, 2005

POMBO, A. F. W. Determinação crioscópica da atividade de água na manteiga. Revista do Instituto de Laticínios "Cândido Tostes", 1987.

PROTZEK, E. C.; FREITAS, R. J. S.; WASCZYNSKJ, N. Aproveitamento do bagaço de maçã na elaboração de biscoitos ricos em fibra alimentar. Boletim Centro de Pesquisa de Processamento de Alimentos, v. 16, n. 2, p. 263-275, 1998a. 
PROTZEK, E. C.; FREITAS, R. J. S.; WASCZYNSKJ, N. Incorporação de fibra do bagaço de maçã em pães de forma. In: LAJOLO, F. M.; MENEZES, E. W. (Ed.). Temas en tecnología de alimentos. México: IPN, 1998b. p. 245-257.

RAUPP, D. S.; MOREIRA, S. S.; BANZATTO, D. A. Aproveitamento de resíduo resultante de indústrias alimentícias como fonte de nutrientes para humanos e animais: aproveitamento de resíduo resultante da industrialização da maçã. Ponta Grossa: Universidade Estadual, 1999. (Relatório de Projeto de Pesquisa Institucional.)

RAUPP, D. S.; SGARBIERI, V. C. Efeito da fibra solúvel de alta viscosidade na ingestão de alimentos, na excreção fecal e no peso corpóreo, em ratos. Brazilian Archives of Biology and Technology, v. 40, p. 863-874, 1997.

RENARD, C. M. G. C.; TRIBAULT, J. F. Composition and physicochemical properties of apple fibres from fresh fruits and industrial products. Lebensm-Wiss U-Technology, v. 24, n. 6, p. 523-527, 1991.

SATO, M. et al. Características de qualidade de bagaço de 11 genótipos de maçã. Ciência e Tecnologia de Alimentos, 2007. (Em análise).

SAURA CALIXTO, F. Fibra dietetica de manzana: Hacia nuevos tipos de fibras de alta calidad. Alimentaria, v. 5, p. 57-61, 1993.
SHAHIDI, F; NACZK, M. Food Phenolics - Sources, Chemistry, Effect, Applications. Pennsylvania: Technomic, 1995. p. 321.

SKLIUTAS, A. R.; Estudo do desenvolvimento de barra dietética de cereais e goiaba desidratada pelo processo de osmose a vácuo com utilização de fruto-oligossacarídeo. 116 p. Tese (Mestrado) Faculdade de Engenharia de Alimentos, Universidade Estadual de Campinas, Campinas, 2002.

TUNGLAND, B. C.; MEYER, D. Nondigestible Oligo and Polysaccharides (Dietary Fiber). Comprehensive Reviews in Food Science and Food Safety, v. 1, p. 73-77, 2002.

WALTER, R. H. et al. Edible fibers from apple pomace. Journal of Food Science, v. 50, p. 747-749, 1985.

WANG, H. J. THOMAS, R. L. Direct use of apple pomace in bakery products. Journal of Food Science, v. 54, n. 3, p. 618-620, 1989.

WOSIACKI, G. Extraction of Pectin From Apple Pomace. Brazilian Archives of Biology and Technology, v. 48, n. 2, p. 259-266, 2005.

WOSIACKI, G.; PHOLMAN, B. C.; NOGUEIRA, A. Características de qualidade de maçãs. Avaliação físicoquímica e sensorial de 15 variedades. Revista da SBCTA, v. 24, n. 3, 2004. 